\title{
Selection of Active Modified Zeolite Catalyst and Kinetics of the Reaction of Selective Oxidative Dehydrogenation of Cyclohexane to Cyclohexadiene 1,3
}

\author{
Agadadash M. Aliyev, Zumrud A. Shabanova, Ulvi M. Najaf-Guliyev, Irada G. Melikova* \\ Institute of Catalysis and Inorganic Chemistry Named after M. Nagiyev of Azerbaijan National Academy of \\ Sciences, Baku, Azerbaijan \\ Email: "
}

Received 1 June 2015; accepted 6 October 2015; published 9 October 2015

Copyright (C 2015 by authors and Scientific Research Publishing Inc.

This work is licensed under the Creative Commons Attribution International License (CC BY).

http://creativecommons.org/licenses/by/4.0/

(c) (i) Open Access

\begin{abstract}
The catalytic activity of the modified zeolites in the reaction of selective oxidative dehydrogenation of cyclohexane to cyclohexadiene-1,3 has been investigated. It has been found that, the catalyst, $\mathrm{Cu} \mathrm{Zn}$ Co Cr-clinoptilolite $\left(\mathrm{Cu}^{2+}-0.5 \%\right.$; $\mathrm{Zn}^{2+}-0.2 \%$; $\left.\mathrm{Co}^{2+}-0.1 \% ; \mathrm{Cr}^{3+}-0.1 \%\right)$ shows the most activity in this reaction. A kinetic scheme of the mechanism of the reaction has been suggested and on the basis of this scheme, kinetic model of the process has been developed. Numerical values of the kinetic parameters were calculated.
\end{abstract}

\section{Keywords}

Kinetics, Oxidative Dehydrogenation, Cyclohexadiene

\section{Introduction}

The alicyclic dienic hydrocarbons are the raw material for the synthesis of various classes of polyfunctional compounds. Functional derivatives of these compounds by reason of the high activity of a multiple bond are used in the synthesis of polymeric and composite materials for special purposes, physiologically active compounds, as well as the chiral synthons for the directed obtaining analogues of natural compounds and medicaments. One of perspective directions of production of cyclic unsaturated hydrocarbons-one-step catalytic conversion of naphthenic hydrocarbons which resources in oil and products of their processing are significant. The

\footnotetext{
${ }^{*}$ Corresponding author.
}

How to cite this paper: Aliyev, A.M., Shabanova, Z.A., Najaf-Guliyev, U.M. and Melikova, I.G. (2015) Selection of Active Modified Zeolite Catalyst and Kinetics of the Reaction of Selective Oxidative Dehydrogenation of Cyclohexane to Cyclohexadiene 1,3. Modern Research in Catalysis, 4, 87-96. http://dx.doi.org/10.4236/mrc.2015.44011 
most widely studied reaction of catalytic dehydrogenation of naphthenes is in anoxic mode [1]-[4]. It is known that this thermodynamically limited reaction proceeds under hard conditions lead to aromatization and resinification of significant part of the hydrocarbon fraction, as well as rapid coking and deactivation of the catalysts.

Oxidative dehydrogenation of naphthenes for obtaining of alicyclic dienichydrocarbons refers to poorly studied heterogeneous catalytic reactions proceed with participation of oxygen. The using of molecular oxygen as an acceptor of hydrogen allows to carry out the process at milder conditions and to prevent the above mentioned difficulties.

The catalytic properties of zeolite catalysts in the oxidation of cyclohexane were investigated in [5]. It was found that over the faujasite mainly proceed the reactions of deep oxidation and dehydrogenation. Narrow porous zeolites (sodalite, erionite, mordenite, clinoptilolite) show selectivity for the formation of cyclohexene by the following scheme:

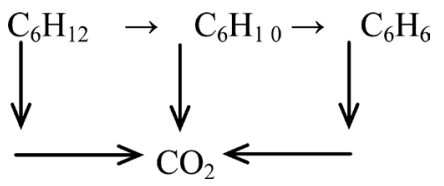

As can be seen from the scheme, there is no formation of the intermediate product cyclohexadiene- 1,3 in consequence of the reaction of oxidative dehydrogenation of cyclohexane over zeolite catalysts. Thus, as a result of analysis of the literature materials, it was found that there isn't any data on obtaining of the valuable product of organic synthesis-cyclohexadiene-1,3.

Cyclohexadiene-1,3 is widely used for the production of a number of physiologically active compounds, preparation of food additives (crocus), floral and fruity perfume (Poison Dior), various polymers, etc. [6]. From this point of view, the synthesis of highly active and selective zeolite-based catalyst for the selective oxidative dehydrogenation of cyclohexane to cyclohexadiene-1,3 is of great theoretical and practical importance.

This paper presents the results of studies of oxidative dehydrogenation of cyclohexane with molecular oxygen in order to identify the conditions of selective formation of cyclohexadiene-1,3 in the presence of modified zeolite catalysts and results of investigation of the kinetics of the reaction.

\section{Methods and Apparatus}

The test of the activity of the prepared zeolite catalysts and a study of kinetics of the reaction were carried out in a flow apparatus with the quarts tube reactor at atmospheric pressure in the range of temperature $280^{\circ} \mathrm{C}-390^{\circ} \mathrm{C}$, space velocity of the gas mixture of $1000-3000 \mathrm{hr}^{-1}$ and a molar ratio of cyclohexane: $\mathrm{O}_{2}: \mathrm{N}_{2}=1:(0,24-1): 5.3$.

The analyses of the reagents and products of the reactions was performed by gas chroma to graphy, using a column filled with Paropak-T (length, $3 \mathrm{~m}$ ) helium as the carrier gas, hot wire detector and program control of the temperature. Analysis of the reaction products is also carried out on gas chromatograph "Agilent 7890" with a mass detector "Agilent-5975” with a column HP-5, length $30 \mathrm{~m}$.

\section{Experimental}

It has been used synthetic zeolites $\mathrm{NaY}\left(\mathrm{SiO}_{2} / \mathrm{Al}_{2} \mathrm{O}_{3}=\lambda=4.2\right), \mathrm{NaX}(\lambda=2.9), \mathrm{NaA}(\lambda=2.0)$ and natural zeolites clinoptilolite $(\lambda=8.68)$ and mordenite $(\lambda=9.6)$ modified by various cations transition and non-transition elements (Zn, $\mathrm{Cu}, \mathrm{Co}, \mathrm{Cr}, \mathrm{Mn}, \mathrm{Fe}, \mathrm{Mg}$, Mo, etc.).

The catalysts were synthesized by an ion exchange method. Modification of zeolites with metal cations was performed by treatment their initial forms in a solution of chloride salts of the corresponding cations. The catalysts prepared on the basis of clinoptilolite and mordenite were subjected to acid treatment before the ion exchange. Before ion exchange the natural zeolites have been treated with $0.5 \mathrm{~N} \mathrm{HCl}$. Number of the cations incorporated into the zeolite was determined by ICP-MS Agilent 7700 and amounted to $0.1 \%-2 \%$ by weight of the zeolite. We used the catalysts with particle size $0.25-0.63 \mathrm{~mm}$ and cyclohexane with purity of $99.5 \%$.

The reaction is carried out in a U-shaped flow reactor. The reactor is placed in a air electric oven with automatic temperature control. Feed of cyclohexane was carried out with a pump. Cyclohexane vapors and nitrogen mixed with oxygen in the mixer located in a thermostated oven, enter the reactor with the catalyst. Temperature stability is maintained in the oven with a contact thermometer. The temperature in the middle of the catalyst bed 
is measured with a thermocouple and recorded with the potentiometer. The reaction unit is directly connected to the analysis system through six-way valve allows the analysis of the reaction mixture without loss. The mixture exiting from the reactor gradually passes through the sample loop and is collected in cooled trap.

\section{Results and Discussion}

The obtained cyclohexadiene was identified by chromatography, IR and UV spectroscopy, and the spectra are shown in Figure 1.

The carried out investigations have allowed to find out both specific and well-known regularities proceeding of heterogeneous catalytic oxidation processes for oxidative dehydrogenation of saturated alicyclic hydrocarbons and to realize selection of an effective catalyst for the reaction.

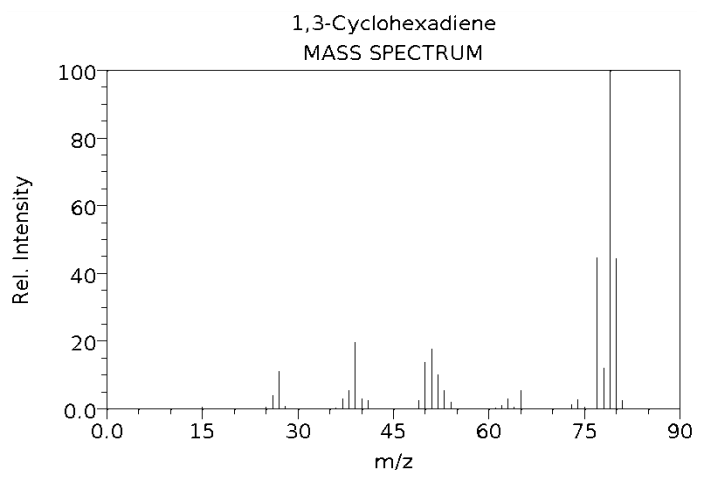

(a)

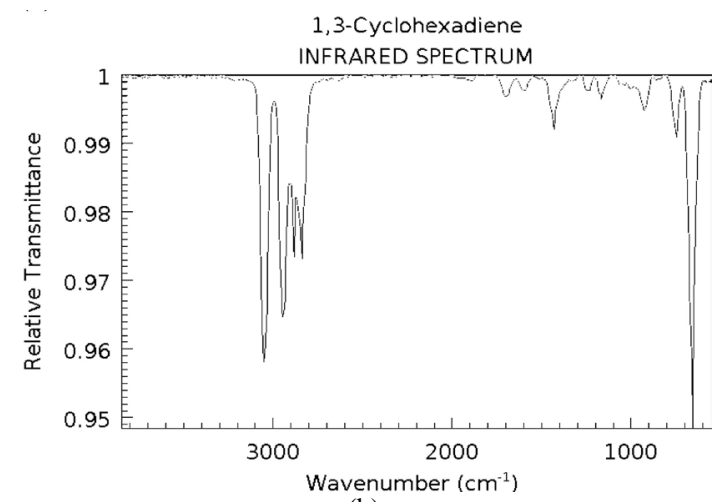

(b)

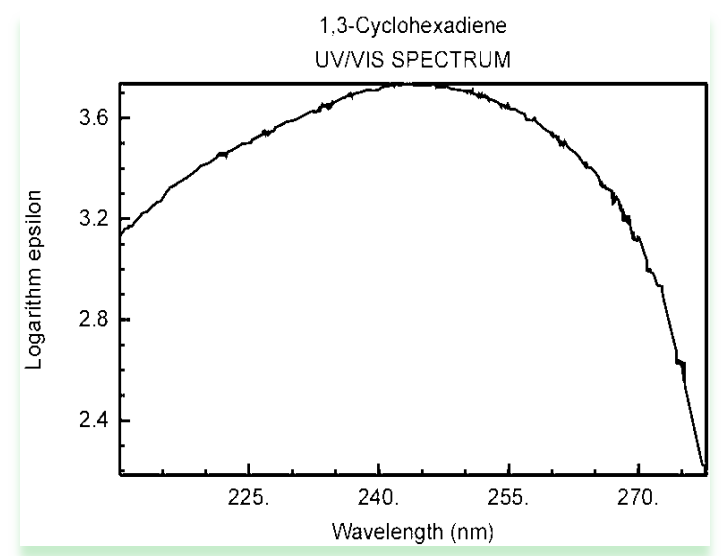

(c)

Figure 1. The spectra of cyclohexadieneş. (a) GC-MS Agilent 5975; (b) IR-spectrometer Nicolet iS10; (c) UV-spectrometer Shimadzu 1800. 
It was found that the conversion of cyclohexane over studied catalysts occurs on the following directions: the oxidative dehydrogenation; partial and deep oxidation. The yield of reaction products depend from the porous structure of the zeolite, its physico-chemical properties as well as the nature and concentration of cations incorporated in the zeolites and reaction conditions.

At first has been investigated catalytic activity of the initial zeolites in oxidative dehydrogenation of cyclohexane.

Table 1 shows the results of investigations of catalytic activity of zeolites not containing metal cations. Results of the study have confirmed that Na-forms of faujasites, internal cavities which are available for molecules of cyclohexane, active only for deep oxidation and these zeolites practically not active for the oxidative dehydrogenation of cyclohexane to cyclohexene and cyclohexadiene [7] [8]. This is probably due to the strong adsorption of cyclohexane on faujasite. In contrast to zeolites with large pores ( $\mathrm{NaX}, \mathrm{NaY})$, narrow porous zeolites characterized with minor surface $\left(8.0-20.0 \mathrm{~m}^{2} / \mathrm{g}\right)$ and small pore size $(4.2-4.9 \AA)$ promote the selective conversion of cyclohexane to cyclohexene. As seen from Table 2, better results were obtained by using of natural clinoptilolite.

Incorporation of thecations of the metals $(\mathrm{Ni}, \mathrm{Co}, \mathrm{Cr}, \mathrm{Zn}, \mathrm{Cu}, \mathrm{Mn}, \mathrm{Mo})$ into the clinoptilolite leads to a change of the catalytic activity of this zeolite. It was established that the influence of these metal cationson the catalytic activity not the same and separately these cationsshow relatively low catalytic activity on the yield of cyclohex-

Table 1. Oxidative dehydrogenation of cyclohexane on different initial zeolites $\left(\mathrm{T}=380^{\circ} \mathrm{C}, \mathrm{V}=2000 \mathrm{u}^{-1}\right.$, cyclohexane: $\left.\mathrm{O}_{2}=1: 1\right)$.

\begin{tabular}{cccccccccc}
\hline \multirow{2}{*}{ Zeolite } & $\mathrm{X}, \%$ & $\mathrm{~S}, \%$ & \multicolumn{5}{c}{ Yield, \% } \\
\cline { 6 - 10 } & & & $\mathrm{C}_{6} \mathrm{H}_{10}$ & $\mathrm{C}_{6} \mathrm{H}_{8}$ & $\mathrm{C}_{6} \mathrm{H}_{6}$ & $\mathrm{C}_{6} \mathrm{H}_{11} \mathrm{OH}$ & $\mathrm{C}_{6} \mathrm{H}_{10} \mathrm{O}$ & $\mathrm{CO}_{2}$ \\
\hline $\mathrm{NaY}$ & 20.4 & - & - & - & 3.1 & 0.3 & - & 16.6 \\
$\mathrm{NaX}$ & 19.2 & - & 0.9 & - & 2.7 & 1.2 & 0.5 & 13.9 \\
$\mathrm{NaA}$ & 22.3 & 5.4 & 16.3 & 1.2 & 0.9 & 2.1 & 0.7 & 1.1 \\
flokite & 16.6 & 7.8 & 12.5 & 1.3 & 1.1 & 0.7 & 0.3 & 0.7 \\
clinoptilolite & 23.5 & 19.5 & 15.8 & 4.6 & 1.7 & 0.3 & 0.8 & 0.3 \\
\hline
\end{tabular}

Table 2. Oxidative dehydrogenation of cyclohexane on a modified natural clinoptilolite $\left(\mathrm{T}=380^{\circ} \mathrm{C}, \mathrm{V}_{\mathrm{o}}=2000 \mathrm{u}^{-1}\right.$, $\mathrm{C}_{6} \mathrm{H}_{12}: \mathrm{O}_{2}: \mathrm{N}_{2}=1: 1: 5.3$ ).

\begin{tabular}{|c|c|c|c|c|c|c|c|c|}
\hline \multirow{2}{*}{ Zeolitecontent, wt.\% } & \multirow{2}{*}{$\mathrm{X}, \%$} & \multirow{2}{*}{ S, \% } & \multicolumn{6}{|c|}{ Yield, \% } \\
\hline & & & $\mathrm{C}_{6} \mathrm{H}_{10}$ & $\mathrm{C}_{6} \mathrm{H}_{8}$ & $\mathrm{C}_{6} \mathrm{H}_{6}$ & $\mathrm{C}_{6} \mathrm{H}_{10} \mathrm{OH}$ & $\mathrm{C}_{6} \mathrm{H}_{10} \mathrm{O}$ & $\mathrm{CO}_{2}$ \\
\hline $\operatorname{Zn}(0.2)$ & 14.3 & 2.8 & 0.7 & 0.4 & 0.3 & $12.1^{*}$ & - & 0.8 \\
\hline $\operatorname{Cr}(0.1 \%)$ & 49.3 & 9.5 & 8.8 & 4.7 & 15.5 & 7.9 & 10.5 & 1.9 \\
\hline $\mathrm{Cu}(0.5 \%)$ & 49.7 & 5.8 & 3.6 & 2.9 & 12.5 & 10.5 & 17.7 & 2.5 \\
\hline Co $(0.1)$ & 41.6 & 9.4 & 6.9 & 3.9 & 9.8 & 6.5 & 10.6 & 3.9 \\
\hline $\mathrm{ZnNi}(0.2: 01)$ & 18.2 & 2.7 & 0.8 & 0.5 & 0.9 & $14.8^{*}$ & - & 1.2 \\
\hline $\operatorname{CuCr}(0.5: 0.1)$ & 39.3 & 13.9 & 0.9 & 5.5 & 9.8 & 7.9 & 8.6 & 6.6 \\
\hline CuSn (05:0.1) & 34.1 & 9.6 & 2.2 & 3.3 & 1.3 & 6.1 & 15.3 & 5.9 \\
\hline CuMn (05:0.1) & 33.9 & 12.1 & 3.8 & 4.1 & 7.5 & - & 13.8 & 4.7 \\
\hline CuFe (0.5:0.25) & 14.6 & 54.1 & 0.6 & 7.9 & 1.7 & 3.7 & - & 0.7 \\
\hline $\operatorname{CoCr}(0.1: 0.1)$ & 44.1 & 18.6 & 5.4 & 8.2 & 9.9 & 10.8 & 5.5 & 4.1 \\
\hline $\mathrm{CoMnCu}(0.1: 0.5: 0.5)$ & 16.3 & 41.7 & 3.5 & 6.8 & 1.3 & - & 3.8 & 0.9 \\
\hline CoMnCr (0.1:0.5:0.5) & 43.1 & 20.6 & 11.3 & 8.9 & 16.7 & - & 4.9 & 1.3 \\
\hline CuZnCo (0.5:0.2:0.1) & 45.6 & 25.8 & 16.7 & 11.8 & 2.1 & 7.2 & 6.5 & 1.3 \\
\hline CoMoCr (0.1:0.5:0.1) & 41.4 & 7.97 & 7.8 & 3.3 & 2.9 & 13.7 & 9.3 & 4.4 \\
\hline CuZnCoCr (0.5:0.2:0.1:0.1) & 35.8 & 65.1 & - & 23.3 & 0.5 & 7.1 & - & 4.9 \\
\hline CuZnCoCr (2:2:1.0:0.5) & 54.4 & 29.7 & 2.5 & 16.2 & 3.9 & 16.9 & 13.5 & 1.4 \\
\hline
\end{tabular}

*yield of hexane. 
adiene. Thus, under the studied reaction conditions, over the samples modified with cations $\mathrm{Zn}^{2+}$ and $\mathrm{Ni}^{2+}$, the reaction of oxidative dehydrogenation of cyclohexane proceeded by destructive dehydrogenation, over clinoptilolite modified with cations $\mathrm{Cu}^{2+}, \mathrm{Mn}^{2+}, \mathrm{Sn}^{2+}$-partial and a deep oxidation, over clinoptilolite modified with cations $\mathrm{Co}^{2+}, \mathrm{Cr}^{3+}, \mathrm{Mo}^{2+}$-dehydrogenation, partial and deep oxidation. It was found that the highest yield of cyclohexadiene observed over the catalyst $\mathrm{Cu} \mathrm{Zn}$ Co $\mathrm{Cr}$-clinoptilolite containing $\mathrm{Cu}^{2+}-0.5 \% ; \mathrm{Zn}^{2+}-0.2 \%$; $\mathrm{Co}^{2+}-0.1 \%$; $\mathrm{Cr}^{3+}-0.1 \%$. Increasing of concentration of these cations in the composition of this catalyst leads to a decrease in yield of cyclohexadiene and increasing the yield product of partial oxidation (Table 2).

Kinetic experiments were performed in a flow apparatus at atmospheric pressure in the temperature range $320^{\circ} \mathrm{C}-380^{\circ} \mathrm{C}$, space velocity $500-3000 \mathrm{~h}^{-1}$, the partial pressures of the reactants $P_{\mathrm{C}_{6} \mathrm{H}_{12}}=0.05-0.14 \mathrm{~atm}$.; $P_{\mathrm{O}_{2}}=0.07-0.25$ atm. Runs performed at several feed rates and using granules of the catalyst $\mathrm{Cu} \mathrm{Zn}$ Co Cr-clinoptilolite with of different sizes showed that external and internal mass transfer effects were negligible under the studied experimental conditions.

The results of the investigations of influence of the partial pressures of the reagents to the proceeding of reaction are shown in Figure 2, Figure 3.

As can be seen from Figure 2, the increasing of $P_{\mathrm{O}_{2}}$ from 0.07 to $0.17 \mathrm{~atm}$. leads to the increasing yield of cyclohexadiene $5.9 \%$ to $13.1 \%$, due to an increase in surface oxygen concentration, and a further increase of $P_{\mathrm{O}_{2}}$ up to $0.25 \mathrm{~atm}$. in practice it has not changed (13.3\%). In all the studied range with increasing oxygen partial pressure yields of the reaction products: cyclohexene, benzene, carbon dioxide, cyclohexanoland conversion of cyclohexane increases.

As can be seen from Figure 3, at a temperature of $360^{\circ} \mathrm{C}$, space velocity of $2000 \mathrm{hr}^{-1}$ and $P_{\mathrm{O}_{2}}=0.14 \mathrm{~atm}$.

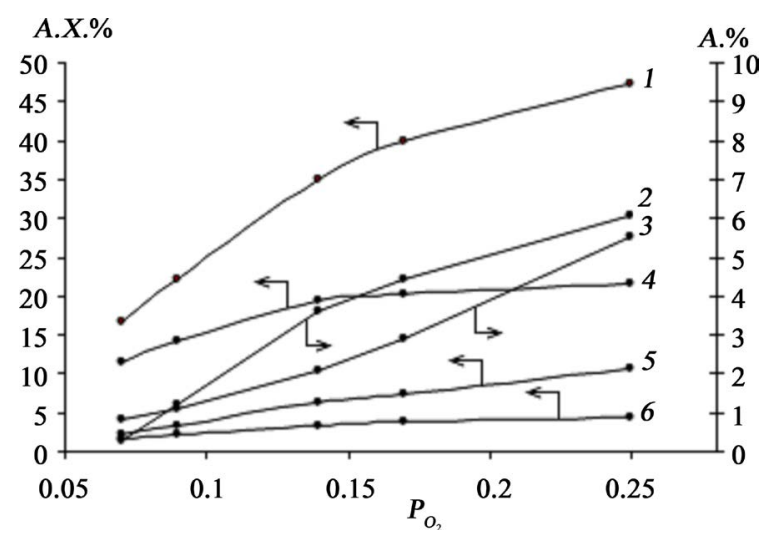

Figure 2. Influence of the oxygen partial pressure on the proceeding of the reaction at $\mathrm{T}=340^{\circ} \mathrm{C}, \mathrm{V}=2000 \mathrm{~h}^{-1}$. Conversion (X) of cyclohexane-1; yields (A) of cyclohexanol-2, carbon-dioxide-3, cyclohexadiene-4, benzene-5 and cyclohexene-6.

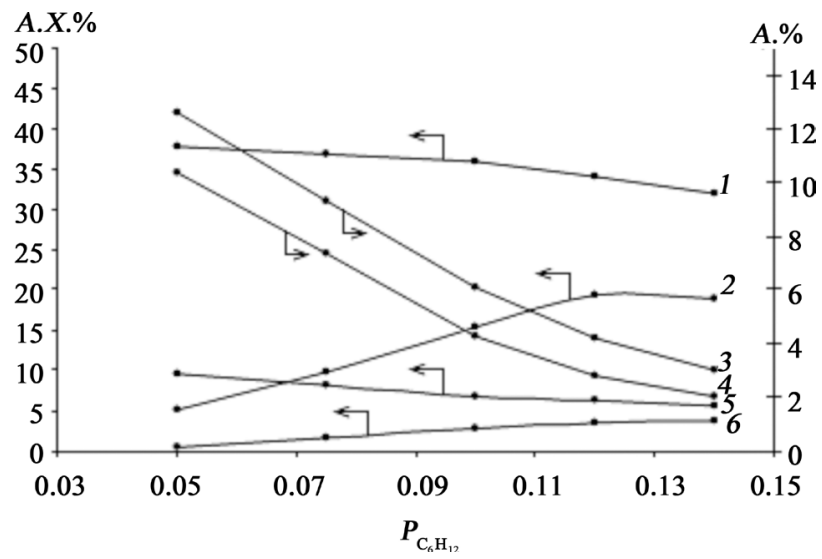

Figure 3. Influence of the cyclohexane partial pressure on the proceeding of the reaction at $\mathrm{T}=360^{\circ} \mathrm{C}, \mathrm{V}=2000 \mathrm{~h}^{-1} \mathrm{Con}$ version (X) of cyclohexane-1; yields (A) of cyclohexadiene-2, cyclohexanol-3, carbon-dioxide-4, benzene-5 and cyclohexene-6. 
with increasing of $P_{\mathrm{C}_{6} \mathrm{H}_{12}}$ from 0.05 to $0.14 \mathrm{~atm}$. the curve of dependence yields of the cyclohexadiene has the extreme character and has a maximum. Maximum yield achieved at $P_{\mathrm{C}_{6} \mathrm{H}_{12}}=0.12 \mathrm{~atm}$. Further increasing of $P_{\mathrm{C}_{6} \mathrm{H}_{12}}$ from 0.12 to $0.14 \mathrm{~atm}$. leads to insignificant decreasing of the yield of cyclohexadiene-1,3 from 11.7 to $11.4 \%$.Decreasing of the yield of cyclohexadiene- 1,3 accompanied by increasing of the yield of cyclohexene and decreasing of the yield of benzene. This is explained with the formation of benzene from cyclohexane proceeds on sequence scheme. Decreasing of yield of carbon dioxide, cyclohexanol, as well as of the conversion due to the fact that for given oxygen partial pressure, relatively high partial pressure of cyclohexane blocks coordination of oxygen to active centers of the catalyst.

From the above described results it follows that the optimum partial pressures of the reactants for achieving the highest yield of 1,3 cyclohexadiene are: $P_{\mathrm{C}_{6} \mathrm{H}_{12}}=0.12 \mathrm{~atm}$. and $P_{\mathrm{O}_{2}}=0.14 \mathrm{~atm}$.

Influence of temperature and space velocity on the proceeding of reaction was studied under optimum $\mathrm{P}_{\mathrm{C} 6 \mathrm{H} 12}$ and $P_{\mathrm{O}_{2}}$ and the results of these investigations are shown in Figure 4 and Figure 5. From Figure 4, follows that, with increasing temperature from $320^{\circ} \mathrm{C}$ to $380^{\circ} \mathrm{C}$ yield of cyclohexadiene- 1,3 increases continuously and reaches $23.3 \%$ at $380^{\circ} \mathrm{C}$, and at higher temperatures $\left(380^{\circ} \mathrm{C}-390^{\circ} \mathrm{C}\right)$ is practically unchanged $(23.3 \%-23.7 \%)$. In all temperature range increasing of yield of benzene due to the fact that, because the high reactivity of cyclohexene and cyclohexadiene rapidly converted to benzene. This suggests that here is realized a sequential scheme

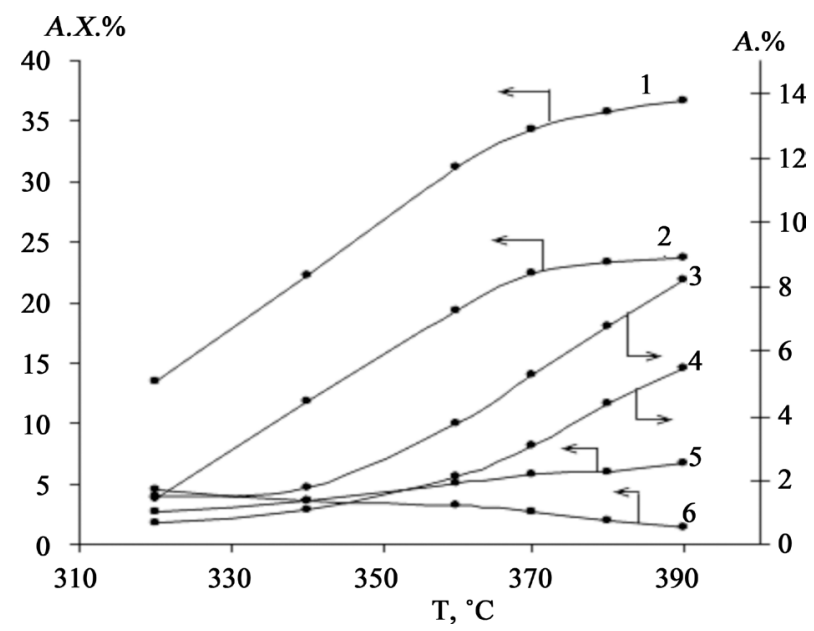

Figure 4. Influence of the temperature on the proceeding of the reaction at a molar ratio of $\mathrm{C}_{6} \mathrm{H}_{12}: \mathrm{O}_{2}: \mathrm{N}_{2}=1: 1: 5.3$ and $\mathrm{V}=$ $2000 \mathrm{~h}^{-1}$ Conversion (X) of cyclohexane-1; yields (A) of cyclohexadiene-2, cyclohexanol-3, carbon dioxide- 4 , benzene-5 and cyclohexene-6.

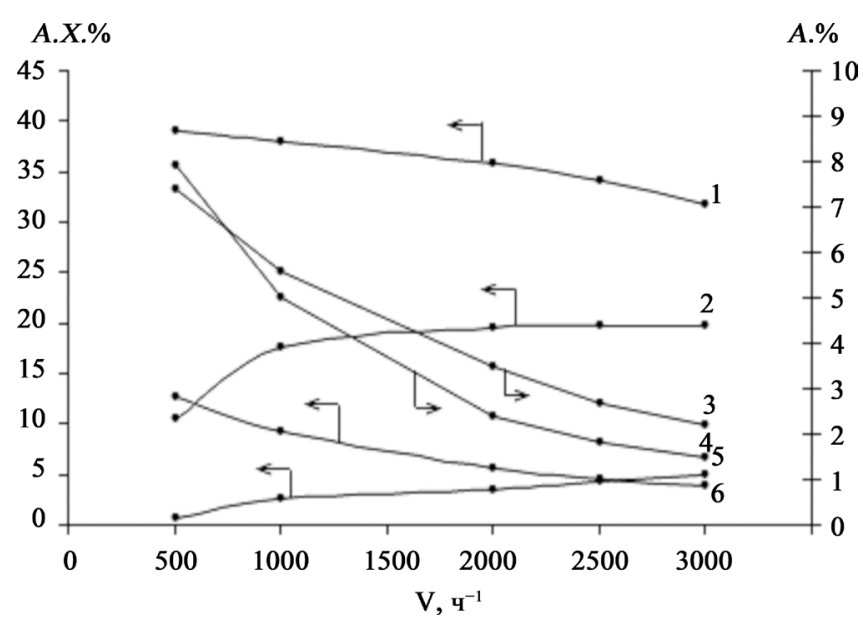

Figure 5. Influence of space velocity on the proceeding of the reaction at a molar ratio $\mathrm{C}_{6} \mathrm{H}_{12}: \mathrm{O}_{2}: \mathrm{N}_{2}=1: 1: 5.3$ and $\mathrm{T}=380^{\circ} \mathrm{C}$ Conversion (X) of cyclohexane-1; yields (A) of cyclohexadiene-2, cyclohexanol-3, carbon dioxide-4, cyclohexene-5 and benzene-6. 
formation of benzene from cyclohexane. With increasing temperature also increases the yield cyclohexanol and $\mathrm{CO}_{2}$. This is due to the fact that at high temperatures, it occurs deep oxidation of cyclohexane, cyclohexene and cyclohexadiene, and also increases the rate of hydration of cyclohexene.

With increasing space velocity from 500 up to $3000 \mathrm{hr}^{-1}$ yield of benzene, carbon dioxide, cyclohexanol and cyclohexane conversion decreases which is associated with decreasing of the contact time (Figure 5) and increasing of the yields of cyclohexene and cyclohexadiene-1,3 thereat the decreasing of the contact time prevents deep oxidative dehydrogenation of cyclohexane, cyclohexene and cyclohexadiene-1,3 these products to benzene, deep oxidation to $\mathrm{CO}_{2}$ and hydration of cyclohexene to cyclohexanol.

According to the experimental data have been suggested the following kinetic scheme for the oxidative dehydrogenation reaction of cyclohexane over $\mathrm{Cu} \mathrm{Zn}$ Co Cr-clinoptilolite catalyst:

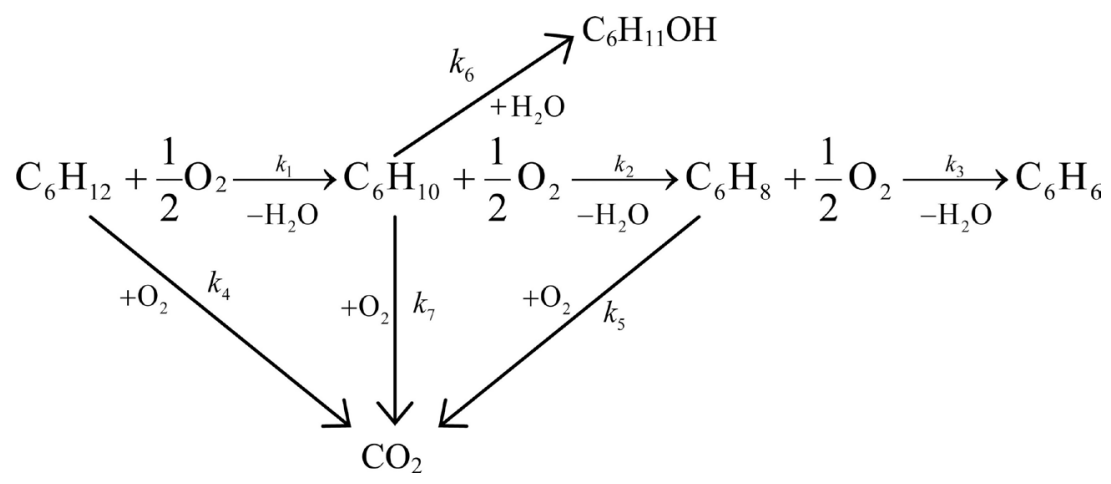

Assuming: cyclohexene formed by the interaction of adsorbed molecules cyclohexane with dissociatively adsorbed oxygen molecules. Then, according to the Langmuir-Hinshelwood mechanism kinetic equation for this reaction is:

$$
r_{1}=\frac{k_{1} K_{1} P_{1} \sqrt{K_{2} P_{2}}}{\left(1+K_{1} P_{1}+\sqrt{K_{2} P_{2}}+K_{3} P_{3}+K_{4} P_{4}+K_{5} P_{5}+K_{6} P_{2}\right)^{2}}
$$

Cyclohexadiene-1,3 is formed by interaction adsorbed molecules of cyclohexene with the dissociatively adsorbed oxygen molecules. Kinetic equation corresponding to this mechanism is:

$$
r_{2}=\frac{k_{2} K_{3} P_{3} \sqrt{K_{2} P_{2}}}{\left(1+K_{1} P_{1}+\sqrt{K_{2} P_{2}}+K_{3} P_{3}+K_{4} P_{4}+K_{5} P_{5}+K_{6} P_{2}\right)^{2}}
$$

Formation of $\mathrm{CO}_{2}$ occurs by interaction of the adsorbed oxygen and cyclohexene molecules. This mechanism corresponds to the kinetic equation:

$$
r_{3}=\frac{k_{7} K_{3} P_{3} K_{6} P_{2}}{\left(1+K_{1} P_{1}+\sqrt{K_{2} P_{2}}+K_{3} P_{3}+K_{4} P_{4}+K_{5} P_{5}+K_{6} P_{2}\right)^{2}}
$$

The reaction of formation of cyclohexanol occurs between adsorbed molecule of cyclohexene and a molecule of water from the gas phase. Kinetic equation corresponding to this mechanism:

$$
r_{4}=\frac{k_{6} K_{3} P_{3} P_{6}}{\left(1+K_{1} P_{1}+\sqrt{K_{2} P_{2}}+K_{3} P_{3}+K_{4} P_{4}+K_{5} P_{5}+K_{6} P_{2}\right)}
$$

According to the kinetic scheme (1) the total rate of formation of cyclohexene can be represented as follows:

$$
r_{\mathrm{C}_{6} \mathrm{H}_{10}}=r_{1}-r_{2}-r_{3}-r_{4}
$$

Deep oxidation of cyclohexadiene-1, 3 occurs by reacting of the adsorbed oxygen and cyclohexadiene molecules and formation of benzene by reacting of the adsorbed molecules cyclohexadiene with the dissociatively adsorbed oxygen molecules. On the basis of this mechanism, we can write the following equation for the rate of 
formation of $\mathrm{CO}_{2}$ and $\mathrm{C}_{6} \mathrm{H}_{6}$ :

$$
\begin{aligned}
& r_{5}=\frac{k_{5} K_{4} P_{4} K_{6} P_{2}}{\left(1+K_{1} P_{1}+\sqrt{K_{2} P_{2}}+K_{3} P_{3}+K_{4} P_{4}+K_{5} P_{5}+K_{6} P_{2}\right)^{2}} \\
& r_{6}=\frac{k_{3} K_{4} P_{4} \sqrt{K_{2} P_{2}}}{\left(1+K_{1} P_{1}+\sqrt{K_{2} P_{2}}+K_{3} P_{3}+K_{4} P_{4}+K_{5} P_{5}+K_{6} P_{2}\right)^{2}}
\end{aligned}
$$

According to the kinetic scheme (1) the total rate of formation of cyclohexadiene-1,3, and benzene are of the form

$$
\begin{gathered}
r_{\mathrm{C}_{6} \mathrm{H}_{8}}=r_{2}-r_{5}-r_{6} \\
r_{\mathrm{C}_{6} \mathrm{H}_{6}}=r_{6}
\end{gathered}
$$

Considering the formation of carbon dioxide by reacting the adsorbed molecules of cyclohexane and oxygen by kinetic equation

$$
r_{7}=\frac{k_{4} K_{1} P_{1} K_{6} P_{2}}{\left(1+K_{1} P_{1}+\sqrt{K_{2} P_{2}}+K_{3} P_{3}+K_{4} P_{4}+K_{5} P_{5}+K_{6} P_{2}\right)^{2}}
$$

and according to the kinetic scheme (1) the total rate of formation of carbon dioxide can be represented by the following equation:

$$
r_{\mathrm{CO}_{2}}=r_{7}+r_{3}+r_{5}
$$

The equation of the total rate of formation of cyclohexanol has the form

$$
r_{\mathrm{C}_{6} \mathrm{H}_{11} \mathrm{OH}}=r_{4}
$$

where $K_{i}$-the adsorption equilibrium constant $\left(K_{i}=K_{i}^{0} \cdot \mathrm{e}^{\frac{Q_{i}}{R T}}\right), k_{i}$-reaction rate constant

$$
k_{i}=k_{i}^{0} \cdot \mathrm{e}^{-\frac{E}{R T}}
$$

The pertinent stoichiometric equations of formation of the reaction products are

$$
\begin{aligned}
& \mathrm{C}_{6} \mathrm{H}_{12}+\frac{1}{2} \mathrm{O}_{2}=\mathrm{C}_{6} \mathrm{H}_{10}+\mathrm{H}_{2} \mathrm{O} \\
& \mathrm{C}_{6} \mathrm{H}_{10}+\frac{1}{2} \mathrm{O}_{2}=\mathrm{C}_{6} \mathrm{H}_{8}+\mathrm{H}_{2} \mathrm{O} \\
& \mathrm{C}_{6} \mathrm{H}_{8}+\frac{1}{2} \mathrm{O}_{2}=\mathrm{C}_{6} \mathrm{H}_{6}+\mathrm{H}_{2} \mathrm{O} \\
& \mathrm{C}_{6} \mathrm{H}_{12}+9 \mathrm{O}_{2}=6 \mathrm{CO}_{2}+6 \mathrm{H}_{2} \mathrm{O} \\
& \mathrm{C}_{6} \mathrm{H}_{10}+8.5 \mathrm{O}_{2}=6 \mathrm{CO}_{2}+5 \mathrm{H}_{2} \mathrm{O} \\
& \mathrm{C}_{6} \mathrm{H}_{8}+8 \mathrm{O}_{2}=6 \mathrm{CO}_{2}+4 \mathrm{H}_{2} \mathrm{O} \\
& \mathrm{C}_{6} \mathrm{H}_{10}+\mathrm{H}_{2} \mathrm{O}=\mathrm{C}_{6} \mathrm{H}_{11} \mathrm{OH}
\end{aligned}
$$

By using these equations, the reaction yield and the initial molar amounts of the reactants we can determine 
the current velocity in the molar flow of cyclohexane, cyclohexene, cyclohexadiene, benzene, carbon dioxide, cyclohexanol, oxygen and water, accordingly by the following equations

$$
\left.\begin{array}{l}
n_{\mathrm{C}_{6} \mathrm{H}_{12}}=n_{\mathrm{C}_{6} \mathrm{H}_{12}}^{0}-\left(A_{1} n_{\mathrm{C}_{6} \mathrm{H}_{12}}^{0}+A_{2} n_{\mathrm{C}_{6} \mathrm{H}_{12}}^{0}+A_{3} n_{\mathrm{C}_{6} \mathrm{H}_{12}}^{0}+A_{4} n_{\mathrm{C}_{6} \mathrm{H}_{12}}^{0}+A_{5} n_{\mathrm{C}_{6} \mathrm{H}_{12}}^{0}\right) / 100 \\
n_{\mathrm{C}_{6} \mathrm{H}_{10}}=A_{1} n_{\mathrm{C}_{6} \mathrm{H}_{12}}^{0} / 100 \\
n_{\mathrm{C}_{6} \mathrm{H}_{8}}=A_{2} n_{\mathrm{C}_{6} \mathrm{H}_{12}}^{0} / 100 \\
n_{\mathrm{C}_{6} \mathrm{H}_{6}}=A_{3} n_{\mathrm{C}_{6} \mathrm{H}_{12}}^{0} / 100 \\
n_{\mathrm{CO}_{2}}=6 A_{4} n_{\mathrm{C}_{6} \mathrm{H}_{12}}^{0} / 100 \\
n_{\mathrm{C}_{6} \mathrm{H}_{11} \mathrm{OH}}=A_{5} n_{\mathrm{C}_{6} \mathrm{H}_{12}}^{0} / 100 \\
n_{\mathrm{O}_{2}}=n_{\mathrm{O}_{2}}^{0}-\left(\frac{1}{2} A_{1} n_{\mathrm{C}_{6} \mathrm{H}_{12}}^{0}+\frac{1}{2} A_{2} n_{\mathrm{C}_{6} \mathrm{H}_{12}}^{0}+8.5 A_{4} n_{\mathrm{C}_{6} \mathrm{H}_{12}}^{0}\right) / 100 \\
n_{\mathrm{H}_{2} \mathrm{O}}=\left(A_{1} n_{\mathrm{C}_{6} \mathrm{H}_{12}}^{0}+A_{2} n_{\mathrm{C}_{6} \mathrm{H}_{12}}^{0}+A_{3} n_{\mathrm{C}_{6} \mathrm{H}_{12}}^{0}+5 A_{4} n_{\mathrm{C}_{6} \mathrm{H}_{12}}^{0}-A_{5} n_{\mathrm{C}_{6} \mathrm{H}_{12}}^{0}\right) / 100
\end{array}\right\}
$$

The partial pressure of the reactants expressed by the equation:

$$
P_{i}=\frac{n_{i}}{\sum n_{i}} P
$$

$A_{1}, A_{2}, A_{3}, A_{4}, A_{5}$-yield of cyclohexene, cyclohexadiene, benzene, carbon dioxide, and cyclohexanol, respectively. $P_{1}, P_{2}, P_{3}, P_{4}, P_{5}, P_{6}$ - partial pressure of cyclohexane, oxygen, cyclohexene, cyclohexadiene, benzene and water, accordingly.

Equations (6) and (9), (10) (12) (13) (14) form the kinetic model of the process.

A kinetic model of the reaction subjected to statistical analysis on the basis of kinetic data. Calculation of pre-exponential factors of the reaction constants, activation energies and heats of adsorption conducted by methods of "rolling admission" and Pauelusing software system "Search" [9], where the objective function has the form:

$$
F=\min \sum_{j=1}^{m} \sum_{i=1}^{n}\left(\frac{A_{j i}^{\text {exp }}-A_{j i}^{\text {calc }}}{A_{j i}^{\exp }}\right)^{2}
$$

$A_{j i}^{\text {exp }}, A_{j i}^{\text {calc }}$-experimental and calculated values of outputs $i$-th component in the $j$-experiment, $m$ - the number of experiments, $n$ - the number of components.

Numerical values of the constants of a kinetic model presented in the Table 3. Calculations showed that the relative error of experimental and calculated data did not exceed 10\% - 15\%.

Table 3. The numerical values of the constants of the kinetic model.

\begin{tabular}{cccc}
\hline & \multicolumn{2}{c}{$E_{i}\left(Q_{i}\right), \mathrm{kkal} / \mathrm{mole}$} \\
\hline $\ln k_{1}^{0}\left(\ln K_{i}^{0}\right)$ & 34.18 & $E_{1}$ & 25.25 \\
$\ln k_{2}^{0}$ & 51.77 & $E_{2}$ & 31.94 \\
$\ln k_{3}^{0}$ & 32.24 & $E_{3}$ & 10.01 \\
$\ln k_{4}^{0}$ & 20.86 & $E_{4}$ & 35.15 \\
$\ln k_{4}^{0}$ & 41.52 & $E_{5}$ & 21.55 \\
$\ln k_{6}^{0}$ & 23.17 & $E_{6}$ & 17.82 \\
$\ln k_{7}^{0}$ & 10.51 & $E_{7}$ & 39.79 \\
$\ln K_{1}^{0}$ & 23.16 & $Q_{1}$ & 2.49 \\
$\ln K_{2}^{0}$ & 1.02 & $Q_{2}$ & 11.00 \\
$\ln K_{3}^{0}$ & 8.75 & $Q_{3}$ & 8.57 \\
$\ln K_{4}^{0}$ & 6.84 & $Q_{4}$ & 11.00 \\
$\ln K_{5}^{0}$ & 25.48 & $Q_{5}$ & 3.19 \\
$\ln K_{6}^{0}$ & 3.027 & $Q_{6}$ & 2.49 \\
\hline
\end{tabular}




\section{Conclusion}

Based on the performed investigations, discussion can be concluded: the proposed kinetic model in the studied range of variation of parameters describes quite well the mechanism of the reaction and can be used to develop a mathematical model of the process.

\section{References}

[1] Pines, H. and Csicery, S.M. (1962) Dehydrogenation, Dehydrocyclization and Isomerization of $\mathrm{C}_{5}-\mathrm{C}_{6}$ Hydrocarbons over Chromia-Alumina Catalysts. Journal of the American Chemical Society, 84, 292. http://dx.doi.org/10.1021/ja00861a032

[2] Yagodovsky, V.D., Pskhu, A.V., Isaeva, N.Yu., Yagodovskaya, T.V., Kifyak, R.A. and Belyaeva, K.S. (2009) Dehydrogenation of Cyclohexane on the Industrial Platinum AP-64 Catalyst Which Was Exposed to Plasmachemical Treatment. Journal of Physical Chemistry, 83, 847-851.

[3] Koel, B.E., Blank, D.A. and Carter, E.A. (1998) Thermochemistry of the Selective Dehydrogenation of Cyclohexane to Benzene on Pt Surfaces. Journal of Molecular Catalysis A, 131, 39-53. http://dx.doi.org/10.1016/S1381-1169(97)00255-0

[4] Biniwale, R.B., Kariya, N. and Ichikawa, M. (2005) Dehydrogenation of Cyclohexane over Ni Based Catalysts Supported on Activated Carbon Using Spray-Pulsed Reactor and Enhancement in Activity by Addition of a Small Amount of Pt. Catalysis Letters, 105, 83. http://dx.doi.org/10.1007/s10562-005-8009-x

[5] Tagiyev, D.B. and Minachev, H.M. (1981) Catalytic Properties of Zeolites in Oxidation Reaction. Russian Chemical Review, L, 1935.

[6] Mironov, V.A., Fedorovich, A.D. and Akhr, A.A. (1983) Synthetic Methods among 1,3-Cyclohexadienes. Russian Chemical Reviews, LII, 104.

[7] Minachev, H.M., Tagiyev, D.B., Zulfugarov, Z.G. and Kharlamov, V.V. (1979) Oxidative Dehydrogenation of Cyclohexane on Cationic Forms of Zeolites. Kinetics and Catalysis, XX, 399.

[8] Coughlan, B. and Keane, M.A. (1990) Catalytic Oxidative Dehydrogenation over $\mathrm{Cu}^{2+}$ Exchanged NaY and KY Zeolites. Catalysis Letters, 4, 223. http://dx.doi.org/10.1007/bf00765938

[9] Shakhtakhtinsky, T.N, Bakhmanov, M.F. and Kelbaliyev, G.N. (1985) Methods of Optimization of Processes of Chemical Engineering with the Computer Programs. Elm, 260. 